Acta Poetica 29-1

PRIMAVERA

2008

\title{
El discurso de Claudio ante el senado (Ann. XI, 24) y la política imperial romana
}

\author{
José Tapia Zúñiga
}

Cornelio Tácito, al igual que los máximos representantes de la historiografía antigua, siguió la tradición de introducir en su obra discursos de algunos personajes. Este recurso respeta rigurosamente la unidad de estilo, requisito fundamental de una obra de arte retórica; por ello, cada discurso se somete a un complejo proceso de reelaboración que lo integre de manera orgánica a la totalidad del texto. Cuando es posible la confrontación del texto 'original' y el 'ficticio', es posible establecer la relación que hay entre el punto de vista del historiador y el del personaje histórico. En este ensayo, se busca establecer la relación entre el punto de vista de Tácito y el del emperador Claudio en torno a uno de los aspectos fundamentales de la política imperial romana: la extensión del ius honorum al ámbito provincial, asunto tratado en el discurso de Claudio ante el senado (Ann. XI, 24).

As the greatest historiographers of ancient tradition, Cornelius Tacitus introduces speeches of the most representative characters to his work. This devise respects the unity of style, fundamental for rhetoric art; meaning that every speech goes through a very complex process of reconstruction that would integrate it in an organic way to the whole text. When it is possible to compare the two versions, original, and fictitious, it is possible as well, to establish the relationship in between the perspective of the historian and that of the historic character. This essay tries to establish the relationship between the perspective of Tacitus and that of Claudius, the Roman emperor, about one basic aspect of the Roman imperial politics: the extension of the ius honorum to the provinces, which was the main target of the speech given by Claudius to the senate.

Palabras clave: Anales, discurso, Claudio, política, imperial, romana 

Acta Poetica 29-1

PRIMAVERA

2008

José Tapia Zúñiga

\section{El discurso de Claudio ante el senado (Ann. XI, 24) y la política imperial romana}

El discurso que Tácito pone en boca del emperador romano Claudio, en el libro XI de sus Anales, se ha considerado como "uno de los pasajes más interesantes de los Anales de Tácito", como "el fragmento sin duda más original de los Anales", o bien, como "el vértice de los mismos", por citar la opinión de sólo dos estudiosos de la obra histórica de Tácito: A. Michel, y E. Paratore. ${ }^{1}$ Ese discurso fue pronunciado por dicho emperador ante el senado, en el año 48 de nuestra era y séptimo de su principado, en favor de un grupo de notables de la región llamada Gallia Comata o Gallia Transalpina ${ }^{2}$ quienes, habiendo obtenido tiempo atrás la ciudadanía romana, ahora "pedían el derecho de alcanzar cargos en la Urbe"; 3 ese acceso a los cargos honoríficos (ius honorum) les permitiría llegar a la dignidad senatorial y, por ende, al gobierno del imperio.

El texto original de ese histórico discurso fue hallado, casi íntegro, en el siglo XVI, y, a partir de su hallazgo, se multiplicaron los temas de investigación y de discusión; entre otros, se pueden señalar los siguientes: el análisis comparativo entre el

${ }^{1}$ Cf. Michel 1973, 155, y Paratore 1962, 500-501.

${ }^{2}$ Se trata del territorio de las Tres Galliae (Gallia Lugdunensis, Gallia Belgica y Aquitania), distintas de la Gallia Narbonensis.

${ }^{3}$ Tac., Ann. XI, 23, 1: ius adipiscendorum in Vrbe honorum expeterent. 
texto original y su reelaboración literaria por parte de Tácito, medio siglo después; la discusión del conocimiento o desconocimiento que Tácito tuvo del texto original; la investigación en torno a las fuentes $\mathrm{y}$, más en concreto, en torno al modelo que tanto Claudio, en la redacción de su discurso, como Tácito, en la reelaboración del mismo, tuvieron a la vista: sin duda, en ellas es indiscutible la presencia de Tito Livio, ${ }^{4}$ maestro de Claudio y modelo predilecto de Tácito. En este ensayo, me interesa señalar, con base en el análisis formal del texto taciteo, cuál es la relación que hay entre el punto de vista de Tácito y el pensamiento de Claudio, en uno de los aspectos fundamentales de la política imperial romana: la extensión del ius honorum al ámbito provincial.

Como parte del contexto de este discurso, considero útil una breve exposición acerca de la presencia de discursos en las obras de los historiadores e historiógrafos de la antigüedad grecolatina, especialmente, en las Historias y Anales de Tácito. La introducción de discursos en las obras históricas fue una práctica tan generalizada, y llegó a tener tanta aceptación, que terminó por convertirse en una arraigada tradición. Por citar algunos nombres, cabe recordar, entre los historiadores griegos, a Tucídides (siglo v a. C.) y, cinco siglos más tarde, entre los latinos, a Tito Livio y a Salustio (finales del siglo I a. C., y principios del siglo I d. C.): en sus obras históricas, todos ellos introdujeron un abundante y variado número de discursos, con características y objetivos peculiares, aunque con importantes coincidencias tanto de forma como de contenido.

La presencia de este recurso en la historiografía antigua, que sin duda tiene un marcado carácter literario, puede tener más de una explicación; al respecto, E. Courbaud hace, entre otros, los siguientes señalamientos: "para el mundo antiguo, no era suficiente presenciar la actuación de los personajes, ellos querían escuchar el sonido de su voz; además, una obra históri-

\footnotetext{
${ }^{4}$ T. Liv. IV, 2-5.
} 
ca sin discursos les parecía incapaz de reproducir fielmente la realidad", y agrega, "mediante los discursos, los historiadores trataban de proporcionar al público una imagen verdadera de la vida cotidiana, y el público la encontraba en la obra de los historiadores". 5 Si estas reflexiones que se hace el humanista francés en torno a la presencia de discursos en los historiadores antiguos son válidas, y yo opino que sí lo son, uno pensaría que los historiadores de la antigüedad debieron reproducir los discursos de sus personajes tal y como fueron pronunciados; sin embargo, sabemos de sobra que esto no fue así, que tal vez ésta ni siquiera fue una preocupación para ellos, ante la unánime convicción de que la historia, sin dejar de ser "maestra de la vida" (magistra uitae), era, ante todo, una obra del arte retórica (opus unum hoc oratorium maxime); 6 para la obra de arte, la unidad de estilo es un requisito fundamental e imprescindible. Así, en aras de este imperativo estético, los historiadores reelaboraron con su propio estilo los discursos de sus personajes, que decidieron incluir en sus obras; a esa tarea la designaron con el verbo inuertere ("traducir"), cayendo así en una inevitable contradicción: para acercarse a la realidad, introducían en sus historias los discursos de sus personajes, pero, al reelaborarlos, inevitablemente se alejaban de la realidad, del mundo de la verdad, para entrar en el campo de la falsedad o, si se quiere, de lo verosímil.

$\mathrm{Y}$, ¿qué se puede decir del historiador romano Cornelio Tácito, que vivió entre las postrimerías del siglo I de nuestra era y el principio del II? De él se puede afirmar que siguió la tradición de sus antecesores porque así convenía a sus indiscutibles dotes oratorias y a su singular sensibilidad artística. Así, principalmente en las Historias, aunque también en los Anales, llama la atención el considerable espacio que ocupan los discursos: discursos en estilo directo, en estilo indirecto,

${ }^{5}$ Cf. Courbaud 1918, 200.

${ }^{6}$ Cic., De Orat. I, 5. 
en estilo mixto; discursos pronunciados por personajes importantes (emperadores, filósofos, generales), por personas sencillas, por multitudes anónimas; discursos dirigidos a los demás, discursos dirigidos a sí mismo (los monólogos). ${ }^{7}$

Como dije antes, Tácito asume la tradición de sus predecesores: modifica los discursos de sus personajes, los reelabora, los inventa, excepcionalmente los transcribe y, cuando considera que nada de esto puede hacer, de plano los suprime. Sin embargo, si se lee cuidadosamente a Tácito, se advierte una muy marcada conducta personal, tal vez, una actitud muy escrupulosa, muy sincera, frente a la alternativa que le presentan, por un lado, las exigencias de estilo, y, por el otro, el imperativo de la verdad. En efecto, si Tácito tiene que citar o transcribir textualmente el discurso de su personaje, lo hace en muy contadas ocasiones y muy a su pesar; lo confiesa con toda sinceridad y pide perdón por lo que está haciendo ("esta vez transcribiré sus propias palabras"); ${ }^{8}$ en la mayor parte de los casos da a entender, mediante ciertas fórmulas que utiliza para dar la palabra a sus oradores, que él sólo se limita a reproducir el sentido general, pero que la forma del discurso, e incluso las ideas, son totalmente suyas ("sus palabras fueron de este tenor", o bien, "comenzó a hablar de este modo"). ${ }^{9}$ Cuando considera que no le es posible reelaborar el texto, lo suprime y explica por qué: Séneca, a punto de morir, había dictado un elocuente discurso a sus secretarios, pero, como tal discurso había sido publicado literalmente y todo el mundo lo había podido leer en su forma original, Tácito "se abstiene de traducirlo en términos diferentes". ${ }^{10}$

Llama fuertemente nuestra atención lo que ocurrió con el discurso que nos ocupa, pues, al igual que el discurso de Sé-

\footnotetext{
${ }^{7}$ Incluso explica la omisión de algún discurso, como el que pronunció Séneca ante sus secretarios poco antes de morir. Véase infra.

${ }^{8}$ Hist. III, 39, 2.

${ }^{9}$ Ann. I, 58, 1; II, 37, 2.

${ }^{10}$ Ann. XV, 63, 3: quae, in uulgus edita eius uerbis, inuertere supersedeo.
} 
neca, también el texto auténtico del discurso del emperador Claudio lo conoció Tácito y lo tuvo entre sus manos, y también lo conoció y lo leyó el público de su tiempo; sin embargo, es un hecho que Tácito no eliminó de sus Anales este discurso, como lo hizo con el de Séneca, sino que lo reelaboró a fondo, dejando a salvo apenas el título del emperador. ${ }^{11}$ Courbaud atribuye ese comportamiento de Tácito a exigencias de carácter estilístico, ${ }^{12}$ explicación sin duda válida, pero incompleta; por mi parte, considero más convincentes las reflexiones de Syme, ${ }^{13}$ quien, sin desatender la indiscutible exigencia de carácter literario, agrega que, dada la importancia y trascendencia del problema, Tácito sintió la apremiante necesidad de un portavoz autorizado y eligió, no precisamente a Claudio, sino a un emperador despersonalizado que, en nombre de Roma, expusiera su personal punto de vista sobre ese importante aspecto de la política imperial, que necesariamente involucraba al príncipe y a los senadores: la asimilación del elemento provincial al senado, $y$, por ende, al gobierno del imperio.

El documento histórico donde se encuentra el texto original de este discurso (la llamada Oratio Claudii Caesaris de iure honorum Gallis dando) es la Tabula Claudiana o Lugdunensis, que fue descubierta casualmente en el año de 1528, en Lyon, Francia, en una casa de campo, propiedad de un tal Roland Gribaud. Es una tabla de bronce, con 1.39 metros de altura y 1.93 de largo (CIL XIII, 1668), que contiene una inscripción a dos columnas, mutilada en unas treinta líneas en su parte superior. El discurso, como dije, fue pronunciado en el 48 d. C., ${ }^{14}$ y registrado en los Acta Senatus, aunque no existe una opinión unánime entre los estudiosos respecto a la fecha en la cual fue elaborada esta inscripción; Carcopino, por ejemplo, sostiene

${ }^{11}$ Ann. XI, 24.

${ }^{12}$ Cf. Courbaud 1918, 205.

${ }^{13}$ Cf. Syme 1971, 417-419.

${ }^{14}$ Ann. XI, 23, 1: ahí, Tácito proporciona los nombres de los cónsules en función: A. Vitellio, L. Vipstano consulibus. 
que el consejo de las Tres Galias (concilium Trium Galliarum) debió de ordenar, tan pronto como el texto del discurso llegó de Roma, entre los años 48-49 d. C., la realización de una copia monumental, para colocarla junto al altar de la confederación, en el templo consagrado a Roma y a Augusto, que era, precisamente, la sede de ese consejo. ${ }^{15} \mathrm{El}$ texto de la inscripción consta de 81 líneas: 40 en la primera columna y 41 en la segunda.

El juicio de la mayor parte de los estudiosos de esta inscripción, en cuanto respecta al estilo, la estructura y el contenido de este discurso de Claudio, es más bien poco favorable; de entre ellos, basten dos ejemplos: A. Michel sostiene que "el estilo del discurso auténtico de Claudio es muy malo, obscuro y rebuscado", ${ }^{16}$ mientras que R. Syme afirma que "el estilo de Claudio es pesado y confuso, pues en su discurso se mezclan erudición y argumentos inadecuados, condescendencia y malicia, sentido común y ultrajante simulación"; ${ }^{17}$ sin embargo, De Vivo opina que la crítica adversa incurre en un grave error de principio, pues "pretende decodificar el registro de un discurso 'oral' utilizando criterios de valoración propios del lenguaje 'escrito', sin tomar en cuenta que el discurso lionés es una simple transcripción y no una reelaboración escrita según las normas de la retórica y de la estilística". ${ }^{18}$ Algunos estudiosos de este documento opinan que se debe tomar en cuenta la considerable laguna del texto - casi 60 líneas -, entre el principio de la primera columna y el principio de la segunda.

Respecto a la estructura, una lectura atenta pone de manifiesto la total ausencia de un plan lógico en el desarrollo del discurso: más de la mitad la ocupa una larguísima digresión, con otras breves digresiones dentro de ella, sobre los dos sistemas de gobierno que antecedieron al principado romano, la monarquía y la república, comenzando desde Rómulo, para ter-

\footnotetext{
${ }^{15}$ Cf. Carcopino 1934, 174 ss.

${ }^{16}$ Cf. Michel 1973, 156.

${ }^{17}$ Cf. Syme 1971, 417.

${ }^{18}$ Cf. De Vivo 1980, 28-29.
} 
minar (líneas 37-40) con una alusión, difícil de explicar, a las conquistas militares de Claudio en ultramar. Luego, el discurso continúa con ejemplos poco afortunados, dando por hecho que la propuesta del emperador, aún no expuesta, no puede ser rechazada; de hecho, como censor, Claudio no tenía ninguna obligación de someterla a la aprobación del senado; finalmente, a la altura de la línea 60, anuncia que ya es tiempo de que exponga ante el senado cuál es el objetivo de su discurso apoyándolo, para colmo, en un argumento falso, pues lo que ocurría con la Galia Narbonense no era legalmente válido para la Galia Comata o Transalpina (líneas 63-72). Con un inexplicable ex abrupto, Claudio finaliza su discurso (líneas 78-81) haciendo referencia a las dificultades del censo en el que por esos días se ocupaba.

Si bien es posible afirmar que el objetivo de Claudio era fortalecer al senado con la asimilación del elemento provincial, también es bien claro que esa inclusión no podía ser indiscriminada, sino válida y duradera sólo para quienes estuvieran dispuestos a actuar incondicionalmente a favor de la autoridad del princeps. Probablemente así se justifique la alusión velada y aparentemente inexplicable al destino fatal de Valerio Asiático y de su hermano (líneas 54-59). ${ }^{19}$

El contenido cabal de este discurso de Claudio no se agota con la simple solicitud del ius honorum por parte de los notables de las Tres Galias, pues también incluye los complejos problemas de la relación entre el príncipe y el senado, y entre el imperio y las provincias; así, el discurso adquiere, ciertamente, un significado general más amplio y, en consecuencia, una mayor importancia. Cabe suponer que Tácito intuyó tal riqueza de contenido, y por eso decidió consagrarle un amplio espacio (Ann. XI, 23-25, 1), no limitándose a dar una simple noticia

\footnotetext{
${ }^{19}$ Décimo Valerio Asiático, originario de Vienna, ciudad de la Galia Narbonense, fue cónsul suplente en el año 35 d.C., y ordinario, en el 46. Fue amigo de Calígula, pero después lo traicionó; en el año 47 fue acusado de conspiración contra Claudio y condenado a muerte (cf. Ann. XI, 1-3).
} 
del discurso imperial, sino reelaborándolo con su propio estilo, y con base en su personal punto de vista histórico (Ann. $\mathrm{XI}, 24)$.

Tal vez por todo esto, como opina R. Syme, ${ }^{20}$ Tácito decidió tratar el asunto en dos etapas: primero, imagina una reunión privada con un grupo de consejeros, en donde, mediante un discurso en estilo indirecto, expone las objeciones de un grupo de senadores que se opone rotundamente a la solicitud gala y, en consecuencia, a la propuesta del príncipe (capítulo 23); luego presenta el discurso de Claudio, que refuta los argumentos de esos senadores (capítulo 24); la exposición concluye con los resultados que obtuvo Claudio con su discurso: para algunos comentaristas, todo un éxito; para otros, más bien un fracaso (capítulo 25, 1).

Por esto, es necesario un rápido vistazo al capítulo 23 , en busca de una mejor comprensión de la forma y el contenido del capítulo 24. De entrada, cabe señalar que el objetivo concreto de la solicitud de los galos no es nada claro; tal como lo expresa Tácito, ellos pedían el derecho de alcanzar cargos en la Urbe ${ }^{21}$ quizá se trata de la obtención del latus clauus, esto es, de la toga de los senadores, que tenía una franja ancha de púrpura en los bordes. Luego, Tácito señala que sobre esta petición hubo muchos y variados comentarios, ${ }^{22}$ aunque, curiosamente, no da cabida a la opinión de los senadores que sí apoyaban la solicitud de los galos, sino sólo al punto de vista de la oposición, sin especificar autores. Enseguida comienza propiamente el discurso de los senadores, que se apoya en dos argumentos fundamentales, ambos inconsistentes: el primero sostiene que Italia no está tan decaída que no sea capaz de proporcionar un senado a su capital, y que, antaño, los indígenas

\footnotetext{
${ }^{20}$ Cf. Syme 1971, 417.

${ }^{21}$ Ann. XI, 23, 1: ius adipiscendorum in Vrbe honorum expeterent.

${ }^{22}$ Ibídem: multus ea super re uariusque rumor.
} 
les habían bastado a los pueblos consanguíneos. ${ }^{23}$ Sin duda, el argumento no sólo es inconsistente, sino también falso, pues Tácito no ignoraba que había sido precisamente el descontento de los pueblos de la península itálica, excluidos de los cargos públicos y discriminados por la nobleza oligárquica, lo que había dado pie a la guerra social y a crear las condiciones que favorecieron la llegada del principado. El segundo argumento que Tácito pone en boca de la oposición hace referencia a todos los violentos enfrentamientos entre Roma y la Galia, desde la más remota antigüedad, incluyendo, con una buena dosis de hipocresía, el asedio al divino Julio en Alesia. A propósito de este segundo argumento, valga este breve comentario: más allá de las contradicciones históricas que encierra, es tal el derroche de solemnidad que utiliza Tácito para presentarlo, que más bien se antoja ver en él una muy bien elaborada ironía, por supuesto, en contra de lo que había dicho la oposición:

que todo lo iban a llenar aquellos ricachones, cuyos abuelos y bisabuelos, como jefes de pueblos enemigos, habían destrozado nuestros ejércitos con la violencia de las armas, y habían asediado al divino Julio en Alesia. ${ }^{24}$

El discurso termina con un periodo intencionalmente muy bien elaborado, sin duda para dejar bien clara la rotunda negativa del ala más conservadora del senado, tanto a la solicitud de la Comata, como a la propuesta del emperador:

Que gozaran cabalmente del título de ciudadanos, pero que no envilecieran la dignidad del senado y la autoridad de los magistrados. ${ }^{25}$

${ }^{23}$ Ann. XI, 23, 2: non adeo aegram Italiam ut senatum suppeditare urbi suae nequiret. Suffecisse olim indigenas consanguineis populis.

${ }^{24}$ Ann. XI, 23, 4: oppleturos omnia diuites illos, quorum aui proauique, hostilium nationum duces, exercitus nostros ferro uique ceciderint, diuum Iulium apud Alesiam obsederint.

${ }^{25}$ Ann. XI, 23, 4: Fruerentur sane uocabulo ciuitatis; insignia patrum, decora magistratuum ne uulgarent. 
Sólo así se entiende el marcado matiz sentencioso de la frase final en que, mediante el atinado empleo del hipérbaton, las formas verbales ocupan los lugares privilegiados del principio y final del periodo: Fruerentur ("que gozaran") ... ne uulgarent ("que no envilecieran"); la frase finaliza con un acertado paralelismo en que, además del homeoptoton que da realce a los objetos directos del último verbo y a los conceptos que encierran: insignia patrum, decora magistratuum ("la dignidad del senado y la autoridad de los magistrados"), llama fuertemente la atención la elipsis del sujeto de uulgarent, que no tiene por qué ser, necesariamente, el sujeto de la oración anterior, dando pie, mediante el recurso de la variación retórica, a una intencional ambigüedad que involucra, muy probablemente, también al emperador como parte del sujeto sobreentendido de uulgarent.

Según el testimonio de Tácito, Claudio, sin titubear, rechaza los argumentos de la oposición, rechazo que el historiador utiliza hábilmente para introducir el discurso de Claudio:

El príncipe no se dejó convencer por estos y parecidos argumentos, e inmediatamente se pronunció contra ellos y, habiendo convocado al senado, comenzó a hablar de esta manera. ${ }^{26}$

Aquí, la frase et statim contra disseruit ("e inmediatamente se pronunció contra ellos") reproduce, sin duda, la expresión et aduersus consules ita disseruit ("y de esta manera se pronunció contra los cónsules"), con la cual Tito Livio introduce el discurso de Canuleyo. ${ }^{27}$

El discurso de Claudio que, en la reelaboración literaria de Tácito, es una concisa y cabal respuesta a las objeciones del núcleo más radical del senado romano, se inicia con una re-

\footnotetext{
${ }^{26}$ Ann. XI, 24, 1: His atque talibus haud permotus princeps et statim contra disseruit et, uocato senatu, ita exorsus est.

${ }^{27}$ T. Liv. IV, 3, 1.
} 
ferencia directa a su persona y a sus propios antepasados (XI, $24,1)$, que le permite enfrentar, sin pérdida de tiempo, el meollo del problema. En efecto, la oposición senatorial utilizaba, como máscara ideológica, la escrupulosa defensa del mos maiorum, esa ancestral tradición sobre la cual descansaba la grandeza del Estado romano, y, en nombre de esos valores, se negaba a aceptar una innovación tan revolucionaria como la concesión del ius honorum a elementos provenientes del ámbito provincial. La referencia a la gens Claudia, y a su fundador, Atta Claudio o Atto Clauso, ${ }^{28}$ originario de la Sabina, región situada al nordeste de Roma, demuestra, por el contrario, que, desde el principio del régimen republicano, familias enteras habían sido aceptadas en la ciudadanía romana e incluso en el rango patricio, con la posibilidad de acceder a todas las magistraturas.

De este modo, Tácito obtiene una inversión de posiciones, gracias a su conocimiento de la historia romana: ${ }^{29}$ la decisión a favor de los notables de la Comata se inserta, lógicamente, en la tradición histórico-política de la res publica; por otra parte, el historiador aprovecha la oportunidad para subrayar que la pretensión senatorial de permitir que los provinciales galos disfrutaran del nombre de ciudadanos romanos, pero que no vieran en ese hecho la autorización de aspirar a las magistraturas, era retrógrada e inaceptable. En efecto, Tácito afirma categóricamente que la aceptación de la extranjera gens Claudia como parte de la ciudadanía romana implicó al mismo tiempo el ingreso a la clase patricia y, en consecuencia, el derecho al ius honorum sin discriminación, como bien lo expresan el atinado uso del adverbio "al mismo tiempo" (simul), y el inmediato paralelismo tanto formal como ideológico:

\footnotetext{
${ }^{28}$ Ann. IV, 9, 2.

${ }^{29}$ Tabl. Lugd. líneas 1-7.
} 
El más antiguo, Clauso, de origen sabino, fue admitido al mismo tiempo en la ciudadanía romana y en las familias de los patricios. ${ }^{30}$

A propósito del hecho histórico al que hace referencia este párrafo, nuevamente llama la atención el estrecho paralelismo de forma y de fondo entre este pasaje de los Anales y aquel del discurso liviano de Canuleyo, ${ }^{31}$ pues ambos traen a colación, en contextos semejantes, el mismo ejemplo, lo que demuestra, además de la presencia de Livio en este discurso de Tácito, que los romanos no tuvieron dificultad para conceder a extranjeros no sólo la ciudadanía, sino también el ius honorum. Porque el ejemplo de lo ocurrido con la sabina gens Claudia no constituye una excepción; razonablemente, Tácito-Claudio puede demostrar que la historia de Roma se caracterizó por una constante aceptación de elementos extranjeros como parte de la ciudadanía romana (XI, 24, 2).

En consecuencia, es justamente la tradición, no sólo romana sino también familiar, la que empuja a Claudio a continuar con esa sabia política de apertura, tomando en cuenta, para el fortalecimiento del senado, a los mejores elementos del imperio: "trayendo aquí lo que de egregio haya habido en cualquier lugar". ${ }^{32}$ Esta frase es una clara réplica de lo dicho por Claudio en su discurso original, a propósito de Augusto, su tío materno, y de Tiberio, su tío paterno, cuyas huellas dice que se propone seguir: "quiso que toda la flor de todas partes, de las colonias y de los municipios, esto es, de los varones buenos y opulentos, estuviera en esta curia". ${ }^{33}$ Del análisis comparativo de ambos textos se desprenden dos señalamientos importantes: por una

\footnotetext{
${ }^{30}$ Ann. XI, 24, 1: antiquissimus Clausus, origine Sabina, simul in ciuitatem Romanam et in familias patriciorum adscitus est.

${ }^{31}$ T. Liv. IV, 3, 14.

${ }^{32}$ Ann. XI, 24, 1: transferendo huc quod usquam egregium fuerit.

${ }^{33}$ Tab. Lugd. líneas 43-44: T. Caesar omnem florem ubique coloniarum ac municipiorum, bonorum scilicet uirorum et locupletium, in hac curia esse uoluit.
} 
parte, el atinado uso de la brevedad, mediante la cual Tácito ha reelaborado y colocado en un contexto diferente uno de los puntos centrales del discurso original, dando así al texto de los Anales un matiz de elocuente ambigüedad, sobre todo, con el uso de los adverbios huc ("aquî") y usquam ("en cualquier lugar"), que sin duda corresponden, respectivamente, a los sintagmas in hac curia ("en esta curia") y ubique coloniarum ac municipiorum ("de todas partes, de las colonias y de los municipios") del discurso original; por la otra, la enorme libertad con la cual el historiador utiliza su fuente, no sólo por razones estilísticas, sino también por motivos ideológicos.

El enunciado que abre el segundo párrafo del discurso ("tampoco ignoro", neque enim ignoro) refleja un matiz claramente polémico, dado que el orador intenta desmitificar la manifiesta y perversa voluntad de la oposición de falsificar la verdad histórica, insinuando, además, una velada acusación de ignorancia en contra del emperador. Así pues, comienza la descripción de algunas de las etapas más importantes que han caracterizado la extensión de la ciuitas y del ius honorum, y en consecuencia, la apertura del senado a elementos extranjeros. Sin embargo, como es fácil comprobar, no se trata de un simple listado de acontecimientos; el periodo oracional que sigue claramente refleja las características propias del estilo taciteo: a esa oración principal siguen tres enunciados elípticos (tricolon): "los Julios de Alba, los Coruncanios de Camerio, los Porcios de Tusculano", estructurados en perfecto paralelismo (Iulios Alba, Coruncanios Camerio, Porcios Tusculo); en ellos se habla del origen de algunas de las más nobles familias romanas; luego, después de un breve paréntesis que marca el paso a una época más reciente ("para no fijarnos tanto en el pasado", ne uetera scrutemur), mediante una oración completiva de infinitivo, coordinada con las precedentes, se hace alusión a la entrada en el senado de varios elementos provenientes de la región de Etruria, de Lucania y, finalmente, de toda 
Italia ("fueron llamados al senado de Etruria y de Lucania y de toda Italia", Etruria Lucaniaque et omni Italia in senatum accitos). Vale la pena subrayar, además del polisíndeton (-que... et) que da solemnidad al enunciado, la elipsis del sujeto ("algunos", quosdam) que utiliza el recurso de la variación retórica para llamar la atención sobre el número cada vez mayor de personajes a los cuales se les otorga el ius honorum. Y así, Tácito-Claudio llega a la afirmación tal vez más importante de todo el discurso: finalmente toda Italia, con su territorio, se ha extendido hasta los Alpes (postremo ipsam [Italiam] ad Alpes promotam), de modo que la ciudadanía romana, con todas sus consecuencias, ya no es privilegio sólo de algunos individualmente, sino derecho de toda la población itálica: "no sólo cada uno individualmente, sino los territorios, los pueblos, se fundieron a nuestro nombre" (ut non modo singuli uiritim, sed terrae, gentes in nomen nostrum coalescerent). Así, mediante una fuerte y bien lograda antítesis reforzada por un asíndeton que imprime velocidad y eficacia a la expresión y al pensamiento, el orador alcanza la cumbre de su razonamiento. En síntesis, Tácito estructuró el segundo párrafo de su discurso valiéndose de una impecable gradación ascendente: en primer lugar, personas por separado, de origen extranjero, son recibidas en Roma; luego, un número indefinido de elementos de una más amplia procedencia se incorporan al senado; por último, sin discriminación alguna, toda Italia se une en el nombre de Roma. En el fondo, esto es precisamente lo que Claudio trata de obtener para los galos: el otorgamiento para la Comata entera (terrae, gentes) del ius honorum, en contraposición con el criterio discriminatorio, absurdo y contrario a la historia, de una parte del senado.

Luego, el orador, en una compendiosa mirada retrospectiva que tiene como objeto poner a la vista de todos la función determinante de la progresiva extensión de la ciudadanía romana, pasa al análisis de acontecimientos más recientes que de- 
muestran, también ellos, la falsa visión de la historia romana que trata de imponer la oposición senatorial. Sin embargo, es oportuno señalar que las primeras líneas del siguiente párrafo del discurso de Tácito-Claudio presentan problemas de interpretación tan serios que, a la fecha, aún no se tiene una explicación plenamente satisfactoria sobre los enigmas formales y de contenido que encierra dicho pasaje:

Entonces hubo una sólida paz en el interior, y frente a los extranjeros logramos el máximo esplendor, cuando los transpadanos fueron recibidos en nuestra ciudadanía, cuando, con el pretexto de establecer nuestras legiones en todo el mundo, habiendo incorporado a los mejores de las provincias, se socorrió al fatigado imperio. ${ }^{34}$

Al respecto, De Vivo piensa "que este pasaje de los Anales presenta una estructura tan compleja, que ha creado enormes problemas de carácter exegético"; 35 por su parte, R. Syme opina "que Tácito, en esta parte de su reelaboración de la Oratio Claudii Caesaris, hace una afirmación sumamente enigmática". ${ }^{36}$

Como el análisis a fondo de este pasaje del discurso de Tácito requiere un espacio y un compromiso que van más allá de los límites de este artículo, y del objetivo que con él me propuse, sólo me ocuparé del planteamiento del problema, y haré algún señalamiento sobre alguna de sus posibles soluciones. Un primer elemento del problema es de carácter histórico: en el año 49 a. C., Julio César otorgó a la región Transpadana o Cisalpina la plena ciudadanía romana ${ }^{37}$ y, en el 42 a. C., después de la batalla de Filipos, los miembros del segundo triunvira-

\footnotetext{
${ }^{34}$ Ann. XI, 24, 3: Tunc solida domi quies; et aduersus externa floruimus, cum Transpadani in ciuitatem recepti, cum, specie deductarum per orbem terrae legionum, additis prouincialium ualidissimis, fesso imperio subuentum est.

${ }^{35}$ Cf. De Vivo 1980, 58.

${ }^{36}$ Cf. Syme 1971, 1058.

${ }^{37}$ D. Casio XLI, 36, 3.
} 
to, alegando un proyecto del dictador (o tal vez inventándolo) acordaron que la región Transpadana pasara a formar parte del territorio itálico; ${ }^{38}$ el segundo elemento es de carácter filológico, y tiene que ver con el valor connotativo del adverbio tunc ("entonces"), primera palabra del párrafo, muy probablemente correlativo de los dos cum temporales ("cuando") que siguen; por último, hay un problema de puntuación, pues ediciones críticas respetabilísimas de los Anales ofrecen, por lo menos, dos formas de puntuación diferentes.

Brevemente, tomando en cuenta la información que precede, lo enigmático de la afirmación de Tácito, o si se quiere, los problemas de carácter exegético que presenta este pasaje de los Anales, se podrían sintetizar así: frente a este texto, la primera pregunta que se hace el lector es ésta: ¿el adverbio "entonces" (tunc), que da inicio al párrafo, se refiere al pasado o al futuro? Si la respuesta es al pasado, se tendría que aceptar que Tácito desconoce la historia de Roma o que miente, pues en el año 49 a. C., e incluso en el 42, es imposible hablar de "una sólida paz en el interior" (solida domi quies), pues Roma se encontraba en plena guerra civil; si, en cambio, como prefieren muchos comentaristas de Tácito, se refiere al futuro, es decir, al principado de Augusto, a la era de paz y concordia que siguió a las guerras civiles, ¿qué tiene que ver la concesión de la ciudadanía romana a los transpadanos? Con seguridad, las explicaciones que dan los comentaristas a esta segunda hipótesis son poco convincentes e imprecisas. Se podría decir, por lo menos, que Tácito es tan rebuscado en este pasaje, que resulta sumamente confuso. Para terminar con este paréntesis, que sin querer ya se hizo largo, un último señalamiento sobre el tema: es posible que esos enigmas y problemas exegéticos se deban a que la puntuación del texto no es la correcta. En efecto, autoridades como C. D. Fisher, en su edición crítica de los Anales, une quies (paz) y floruimus (logramos el máximo esplendor),

${ }^{38}$ D. Casio XLVIII, 12, 5. 
poniendo una coma después de floruimus; sin embargo, tal vez tomando en cuenta que et no es siempre y necesariamente una conjunción copulativa, sino que también puede tener una función dinámica, como se puede comprobar en Ann. XI, 23, 2, E. Koestermann, también en su edición crítica de los Anales, utilizó antes de et un punto y coma: Tunc solida domi quies; et aduersus externa floruimus cum Transpadani in ciuitatem recepti, cum [...] subuentum est. Por supuesto que, con esta lectura, desaparece el problema del que se habló anteriormente; sin embargo, surge una nueva interrogante: si esta puntuación fuera realmente la correcta, ¿cuál sería, entonces, la tesis del orador? Queda pendiente la respuesta.

Además de lo dicho, cabe añadir que llama la atención el escrupuloso paralelismo que utilizó Tácito para construir este periodo, pues a las dos oraciones principales corresponden dos subordinadas temporales unidas anafóricamente por la conjunción "cuando" (cum), sin duda para hacer énfasis en el hecho indiscutible de que una sabia política de apertura había significado para Roma, al mismo tiempo, estabilidad interna y seguridad frente al mundo exterior ("sólida paz en el interior, y frente a los extranjeros logramos el máximo esplendor"); el oportuno empleo de una triple variación retórica, que consiste en: a) cambio de sujeto (quies, "paz"... nos, "nosotros"); b) elipsis en la primera oración, y verbo expreso ("logramos el máximo esplendor", floruimus); c) un locativo (en el interior, domi) corresponde a un circunstancial de lugar ("frente a los extranjeros", aduersus externa), señala que se trata de dos momentos bien diferentes de la historia romana, a pesar de su estrecha relación en el aspecto político: la paz en el interior y la seguridad externa.

La estructura sintáctica de las dos oraciones subordinadas que siguen es idéntica a la de las dos oraciones principales que anteceden, pues también en estos enunciados Tácito utilizó el paralelismo, en este caso, anafórico ("cuando... cuando", 
cum...cum), y la variación retórica: la primera oración está construida en forma personal, con elisión del verbo auxiliar ("cuando los transpadanos fueron recibidos en nuestra ciudadanía", cum transpadani in ciuitatem recepti), y la segunda en forma impersonal, con el verbo expreso ("cuando, con el pretexto de establecer nuestras legiones en todo el mundo, habiendo incorporado a los mejores de las provincias, se socorrió al fatigado imperio", cum specie deductarum per orbem terrae legionum additis prouincialium ualidissimis fesso imperio subuentum est). De la mayor complejidad de este segundo enunciado es posible deducir la intención del orador: hacer hincapié en el hecho de que la estabilidad política en el periodo augusteo depende no sólo de la atinada solución al problema de la unidad itálica, sino también de la apertura a los mejores elementos de las provincias, mediante la creación de colonias de veteranos militares ("con el pretexto de establecer nuestras legiones", specie deductarum... legionum). Ésta es, sin duda, la implícita respuesta política que Tácito-Claudio da a la discriminatoria oposición de la nobleza latina: el reconocimiento de los méritos y derechos de la Italia entera y de los mejores elementos provenientes de las provincias.

Enseguida, confirma con ejemplos, como en el discurso original, ${ }^{39}$ que su propuesta a favor de la Galia Comata no se puede señalar como una peligrosa novedad, sino que está en perfecta armonía con la tradición romana; por ello, hace referencia a los Balbos, que habían venido de Hispania, ${ }^{40}$ y a varones no menos ilustres provenientes de la Galia Narbonense - posible referencia, entre otros, a Julio Agrícola, originario de Foro Juliano, en la Galia Narbonense, suegro de Tácito, a quien el historiador no nombra, tal vez por modestia: “¿Acaso

${ }^{39}$ Tabl. Lugd. líneas 63-71.

${ }^{40} \mathrm{Sin}$ duda se trata de los dos Balbos, tío y sobrino, mejor conocidos como Lucio Cornelio Balbo el Mayor, primer extranjero que obtuvo el consulado, en el año 40 a. C., y de L. C. Balbo el Menor, primer extranjero que obtuvo el triunfo por sus hazañas en África, hacia el año 20 a. C. 
nos arrepentimos de que los Balbos desde Hispania y varones no menos insignes desde la Galia Narbonense hayan pasado a nosotros?"41

Esa amplia disertación sobre el proceso de extensión de la ciuitas romana y del ius honorum, hasta llegar a la provincia de Hispania y a la Narbonense, es decir, al ámbito provincial, termina con una afirmación llena de contenido, que el orador utiliza para rebatir, de una vez por todas, las objeciones de la oposición senatorial: los descendientes de aquellos ilustres varones provinciales llegados a Roma tiempo atrás, ahora ocupan un lugar en el senado, se les puede señalar con el dedo, y sobresalen por su gran amor a la patria común: "Aún quedan descendientes suyos, y no son inferiores a nosotros en el amor a esta patria". ${ }^{42}$ La frase, totalmente tacitea, pues no tiene correspondencia en el discurso original, llama la atención por la forma en que está estructurada, pues el orador, mediante el adecuado empleo del hipérbaton, coloca el sustantivo "amor", lleno de connotación afectiva, en el centro del enunciado, y las formas verbales, "quedan" (manent) y "son inferiores" (concedunt), al principio y al final respectivamente, para dar solemnidad, y para decirle a la nobleza latina senatorial que su angustiosa preocupación por los asuntos públicos (res publica) y por la tradición (mos maiorum) es totalmente infunda$\mathrm{da}$, pues los hechos demuestran, por el contrario, que los lazos que unen a los nuevos ciudadanos (homines noui) con Roma son tan fuertes y duraderos como el amor.

En el párrafo cuarto, tras exponer exhaustivamente el tema de la concesión del ius honorum a los extranjeros, el discurso taciteo de Claudio sufre un repentino y aparentemente inexplicable cambio de tono, que algunos comentaristas tratan de explicar como una digresión:

\footnotetext{
${ }^{41}$ Ann. XI, 24, 3: Num paenitet Balbos ex Hispania nec minus insignes uiros e Gallia Narbonensi transiuisse?

${ }^{42}$ Ibídem: Manent posteri eorum nec amore in hanc patriam nobis concedunt.
} 
¿Cuál otra fue la causa de la ruina de los lacedemonios y de los atenienses, aunque poderosos en armas, sino el que a los vencidos los separaban como a extranjeros? ${ }^{43}$

En mi opinión, no se trata de una digresión, sino de uno de los momentos más significativos del discurso: nada más y nada menos que de la síntesis, confirmación y reconformación de lo expuesto anteriormente, valiéndose de un testimonio histórico traído desde fuera: el exemplum de Esparta y Atenas, ciudades que, a pesar de ser muy poderosas en armas, fracasaron rotundamente en su proyecto imperialista, por su errónea política excluyente pues, encerradas en un racismo a ultranza, trataron siempre a los pueblos conquistados como extranjeros (pro alienigenis). Al contrario, la gradual apertura de Roma y la constante asimilación, como parte del imperio, de los enemigos de ayer, representan para la res publica romana una riqueza inagotable de fuerzas renovadas, y una garantía de paz interna y de seguridad externa. Esta referencia a la historia antigua de Esparta y Atenas no se encuentra en la parte del discurso original de Claudio; sin embargo, aun siendo pura creación tacitea, no se podría calificar de inverosímil, pues, si se toma en cuenta el interés de Claudio, alumno de T. Livio, como ya se dijo antes, por la erudición histórica, una reflexión de esta índole, fundada en el análisis de la historia, se acomoda perfectamente como parte de su personalidad.

A este ejemplo sigue una nueva confirmación: para hacer hincapié en la diferencia estructural entre el imperialismo romano y el griego, el orador toma como punto de referencia para su siguiente reflexión los orígenes más remotos de la historia del imperio romano, trayendo a consideración la sabia conducta de su fundador:

\footnotetext{
${ }^{43}$ Ann. XI, 24, 4: Quid aliud exitio Lacedaemoniis et Atheniensibus fuit, qua-
} mquam armis pollerent, nisi quod uictos pro alienigenis arcebant? 
Por el contrario, Rómulo, nuestro fundador, se distinguió tanto por su sabiduría, que a muchos pueblos en un mismo día los tuvo como enemigos y luego como ciudadanos. ${ }^{44}$

El periodo tiene una cuidadosa elaboración retórica: en la oración principal, valiéndose del hipérbaton, el nombre del fundador del imperio romano se coloca en el centro del enunciado y el verbo al final, para llamar la atención del oyente o del lector (At conditor nostri, ROMVLVS, tantum sapientia VALVIT), como lo hace en la oración consecutiva que sigue, mediante la antítesis, el asíndeton y la variación retórica (ut plerosque populos eodem die hostes, dein ciues habuerit): aquí, Tácito afirma que esa amplia visión respecto a los pueblos extranjeros, que se remonta al fundador de la Ciudad, Rómulo, fue una libre y consciente decisión (sapientia), en la cual se ha inspirado siempre la tradición romana, y en la que Claudio desea continuar, siguiendo las huellas de sus antepasados, incluida su familia.

Y concluye el orador la larga refutación del primer argumento de la parte opositora del senado (Ann. XI, 23, 2), con una síntesis que abarca y une estrechamente al periodo regio con la república, y a ésta con el principado, en esa sabia e ininterrumpida actitud de apertura y asimilación del mundo extranjero, como parte integrante de la sociedad y del gobierno del Estado romano: desde pronto gobernaron al pueblo romano hombres venidos de fuera (Aduenae in nos regnauerunt); luego, casi al principio del régimen republicano, hijos de libertos, es decir, hombres que no eran de origen romano, ocuparon cargos públicos (non repens, sed priori populo libertinorum filiis magistratus mandare). Refiere T. Livio que ya Apio Claudio el Ciego, en el año 310 a. C., había logrado introducir en el senado, contra la voluntad de sus colegas, a los hijos de

\footnotetext{
${ }^{44}$ Ann. XI, 24, 4: At conditor nostri, Romulus, tantum sapientia ualuit ut plerosque populos eodem die hostes, dein ciues habuerit.
} 
algunos libertos. ${ }^{45}$ Resulta, pues, que el verdadero continuador de la política republicana (priori populo) es el emperador y no los senadores, que se empeñaban en aparecer como los legítimos herederos de la res publica.

Ahora, tras haber destruido el primer argumento de la parte opositora del senado, y seguro de sí mismo por el sobrado apoyo recogido de la tradición romana, Claudio inicia la refutación del segundo y último argumento de la oposición senatorial, sustentado en la sangrienta hostilidad de los galos contra el pueblo romano, desde la toma del Capitolio por la tribu celta de los senones, habitantes de la Galia Lugdunense, en el año 390 a. C., hasta el asedio de Julio César, en la ciudad de Alesia, en el año 53 a. C. ${ }^{46}$ (Ann. XI, 23, 4).

A la artificial y fingida solemnidad que los senadores habían utilizado en la presentación de este argumento, Tácito contrapone la ironía del emperador, valiéndose de un periodo que avanza con ritmo alegre, ágil y burlón, donde tesis, antítesis, interrogación retórica e ironía se combinan armónicamente para poner en completa evidencia lo absurdo y antihistórico del argumento de la oposición:

Ciertamente combatimos contra los senones; sin duda los volscos y los ecuos nunca desplegaron sus ejércitos contra nosotros. Fuimos hechos prisioneros por los galos, pero también entregamos rehenes a los etruscos y soportamos el yugo de los samnitas. ${ }^{47}$

En este quinto párrafo del discurso taciteo de Claudio, llama la atención la voluntad deliberada de presentar a galos e itálicos en una relación de completa igualdad: a pesar de que ambos,

\footnotetext{
${ }^{45}$ T. Liv. IX, 29.

${ }^{46}$ B. G. VII, 68 ss.

${ }^{47}$ Ann. XI, 24, 5: At cum Senonibus pugnauimus; scilicet Vulsci et Aequi numquam aduersam nobis aciem instruxere. Capti a Gallis sumus; sed et Tuscis obsides dedimus et Samnitium iugum subiimus.
} 
en igual forma y desde tiempo atrás, fueron enemigos del pueblo romano, al que en más de una ocasión combatieron, derrotaron y humillaron, y, aunque el ala latina del senado siempre consideró a los itálicos como alienigenae, éstos ya ocupaban un lugar en el senado, mientras que a los galos de la Comata se les seguía negando el ius honorum. Es relevante el adecuado uso de los adverbios scilicet ("sin duda") y numquam ("nunca") para hacer más patente la ironía, y el uso atinado del homeoteleuton pues, mediante la semejanza fónica, el orador hace hincapié en esa relación de igualdad entre itálicos y provinciales, implícita en la respuesta de Claudio (...pugnauimus... sumus... dedimus... subiimus).

Además, por si la historia verdadera de la relación entre el pueblo galo y el romano no hubiera sido suficiente para la refutación, el orador agrega la siguiente reflexión, históricamente verdadera en su primera parte, falsa en la segunda: si se analizan todas las guerras de conquista llevadas a cabo por los romanos, ninguna fue tan breve como la guerra de las Galias; además, a la guerra contra los galos siguió una paz continua y duradera:

Y con todo, si se pasa revista a todas las guerras, ninguna se terminó en un tiempo más breve que la que hicimos contra los galos. Desde entonces, la paz fue continua y confiable. ${ }^{48}$

Sobre la forma de esta parte del discurso, hay que destacar la doble elipsis del verbo, típica de la brevedad tacitea, que aparece en las dos oraciones principales: confectum [est] ("se terminó") ... pax [fuit]... ("la paz fue...").

$\mathrm{El}$ argumento de esta parte del texto, en todas sus partes, está tomado del discurso original de Claudio, ${ }^{49}$ como lo demuestran las siguientes correspondencias: "ninguna se ter-

\footnotetext{
${ }^{48}$ Ann. XI, 24, 6: Ac tamen, si cuncta bella recenseas, nullum breuiore spatio quam aduersus Gallos confectum. Continua inde ac fida pax.

${ }^{49}$ Tabl. Lugd. líneas 72 ss.
} 
minó en un tiempo más breve que la que hicimos contra los galos" (nullum breuiore spatio quam aduersus Gallos confectum) corresponde a la frase claudiana: "que tuvieron ocupado al divino César con una guerra de diez años" (quod bello per decem annos exercuerunt divom Iulium, líneas 72-73); "Desde entonces, la paz fue continua y confiable" (Continua inde ac fida pax) corresponde a estas expresiones del discurso original: "confianza inmutable" (immobilem fidem, línea 74) y "paz segura y sin recelo" (tutam... securamque... pacem, línea 76); finalmente, el enunciado hipotético: "si se pasa revista a todas las guerras" (si cuncta bella recenseas) reproduce la construcción del original: "si alguien ve esto" (si quis hoc intuetur, línea 72). Como insinué antes, la primera afirmación que Tácito pone en boca de Claudio es, sin duda, comprobable históricamente, pues consta que Julio César inició la conquista de las Galias en el año 58 a.C. y la concluyó en el 50, en no más de 10 años); sin embargo, como no es posible pasar por alto el levantamiento de Julio Sacróviro y Julio Floro, en el año 21 d. C., ${ }^{50}$ amén de la sublevación de Julio Clásico y Julio Tutor, en los años 69-70 d. C., ${ }^{51}$ afirmar que a la guerra de las Galias siguió "una paz continua y duradera", podría interpretarse o bien como una ironía velada de Tácito en contra del emperador, o bien como un intento deliberado del historiador por minimizar la importancia que tuvieron dichos levantamientos.

Luego, no conforme el orador con haber refutado cabalmente las infundadas y antihistóricas acusaciones en contra de los galos, afirma que ya es oportuno y necesario que se les otorgue un lugar en el senado; en efecto, sería absurdo e inaceptable que los habitantes de la Comata, cuyo proceso de asimilación ya había llegado a su término, después de más de un siglo, continuaran privados del pleno ius honorum, cuyo otor-

\footnotetext{
${ }^{50}$ Ann. III, 40-46.

${ }^{51}$ Hist. V, 19-22.
} 
gamiento habría permitido, sin duda, una saludable comunión de intereses, provechosa para ambos pueblos:

Ya con nuestras costumbres, artes, parentescos, mezclados, que nos traigan su oro y sus riquezas, en lugar de tenerlas sólo para ellos. ${ }^{52}$

Con estas palabras, Tácito-Claudio refuta, de paso, otra de las objeciones contenida en Ann. XI, 23, 4: "Decían que todo lo iban a llenar aquellos ricachones..."

El claro matiz antitético del enunciado que nos ocupa, marcado por los vocablos mixti / separati, crea una estructura bipartita reforzada por la similicadencia inferant ... habeant, que pone en evidencia la absurda contradicción entre la situación de hecho y la situación de derecho que caracteriza las relaciones entre los pueblos galos y Roma. También llama la atención el recurso estilístico utilizado por el orador para señalar cada uno de los momentos a través de los cuales se llevó a cabo la romanización de los galos: una gradación ascendente, estructurada en un tricolon asindético ("costumbres, artes, parentescos": moribus, artibus, adfinitatibus), en que, además, Tácito une estrechamente el segundo y tercer elemento del enunciado, valiéndose de la aliteración, para imprimir al pasaje un indiscutible sabor arcaizante.

Así, el discurso imperial llega a su parte final: la peroración (XI, 24, 7). En ella, Tácito recoge el argumento utilizado por Claudio al comienzo de su discurso original, ${ }^{53}$ para invitar a los senadores a reflexionar sobre la enorme cantidad de innovaciones que registra la historia institucional del pueblo romano, comenzando desde la fundación de su ciudad capital. Sin embargo, el historiador traslada la reflexión del ámbito particular, la historia de las instituciones romanas, a todo el campo

${ }^{5}$ Ann. XI, 24, 6: Iam moribus, artibus, adfinitatibus nostris mixti, aurum et opes suas inferant potius quam separati habeant.

${ }^{53}$ Tabl. Lugd. líneas 2-7. 
de la historia, y expresa su pensamiento mediante una sententia cuidadosamente elaborada: todo lo que está sólidamente cimentado en la tradición constituye necesariamente una res nоиа; el paso del tiempo hace que las cosas nuevas se conviertan en viejas: "Todas las cosas, senadores, que ahora se consideran antiquísimas, fueron nuevas". 54

En seguida, mediante una apretadísima síntesis, Tácito hace hincapié en el progresivo otorgamiento del ius honorum, primero a los plebeyos, luego a los latinos, y finalmente a todos los demás pueblos de Italia (plebei magistratus post patricios, Latini post plebeios, ceterarum Italiae gentium post Latinos), argumento sobre el cual el historiador ha apoyado todo su discurso, para demostrar lo incongruente y antihistórico del alegato senatorial al mos maiorum.

En la estructura retórica de esta parte del discurso, llama la atención el uso reiterativo del mismo esquema estilístico utilizado por el orador al abordar los asuntos más importantes de la discusión; en este caso, se trata de una gradación descendente en la cual, mediante un tricolon reforzado por el asíndeton, el paralelismo en su parte inicial y la variación retórica en su tercer elemento, donde el sujeto está sobreentendido, el orador llega a ese momento histórico de las instituciones romanas que más interesa políticamente a Claudio: el otorgamiento de la ciudadanía y del ius honorum a todos los demás pueblos de Italia (ceterarum Italiae gentium), extranjeros respecto a los latinos, del mismo modo que los galos.

La parte final de la peroración concluye con una sententia más, íntimamente relacionada con la anterior y reforzada, también ésta, por una antítesis, en la cual se hace énfasis en el dinamismo de la tradición romana, caracterizada por un proceso de ininterrumpida renovación: también esta decisión mía, dice Claudio, algún día será vista como ejemplar y se convertirá en

\footnotetext{
${ }^{54}$ Ann. XI, 24, 7: Omnia, patres conscripti, quae nunc uetustissima creduntur, noua fuere.
} 
tradición: "También esto envejecerá, y lo que hoy defendemos con ejemplos, estará entre los ejemplos". 55

Tácito concluye la última parte de la peroración de este discurso, reproduciendo el esquema de la parte final del discurso que, en estilo indirecto, había puesto en boca del senado (Ann. XI, 23, 4); ambos periodos encierran el tono solemne de sententia, reforzada por el empleo atinado del hipérbaton, mediante el cual las formas verbales están colocadas, en ambos casos, al principio y al final del enunciado (Fruerentur... ne uulgarent / Inueterascet... erit).

De los resultados obtenidos por Claudio con este discurso, Tácito habla al comienzo del capítulo siguiente de sus Anales; allí dice que al discurso siguió un decreto del senado, en virtud del cual los eduos fueron los primeros en obtener el derecho de senadores en la Urbe, en atención a la antigüedad del pacto que los unía con los romanos y porque la relación entre ambos pueblos era tan estrecha, que ellos eran los únicos de entre los galos que usaban el nombre de hermanos del pueblo romano:

Tras un decreto del senado que siguió al discurso del príncipe, los eduos fueron los primeros que obtuvieron el derecho de senadores en la Urbe. Tal derecho fue otorgado en virtud de un antiguo pacto, y porque son los únicos de los galos que usan el título de hermanos del pueblo romano. ${ }^{56}$

Por supuesto que no todos los comentaristas de la obra de Tácito interpretan de igual forma este pasaje de los Anales; algunos estudiosos, como De Vivo, opinan que el discurso del emperador resultó todo un éxito, pues "al discurso imperial, siguió inmediatamente la decisión del senado de otorgar el

${ }^{55}$ Ann. XI, 24, 7: Inueterascet hoc quoque, et, quod hodie exemplis tuemur, inter exempla erit.

${ }^{56}$ Ann. XI, 25, 1: Orationem principis secuto patrum consulto, primi Aedui senatorum in Vrbe ius adepti sunt. Datum id foederi antiquo et quia soli Gallorum fraternitatis nomen cum populo Romano usurpant. 
ius honorum a los notables de las Galias, comenzando por los eduos, antiguos aliados de Roma"; 57 E. Paratore, como otros, piensa que el éxito del discurso de Claudio fue más bien limitado, y que mejor se debería hablar de un fracaso:

En el fondo, no se han equivocado los estudiosos que se han empeñado en determinar los límites de la concesión otorgada por el senado, al término del discurso de Claudio, y que en el primer párrafo de Ann. XI, 25 han querido reconocer una limitación a la propuesta del emperador; en efecto, en Ann. XI, 23 se habla de primores Galliae, mientras que en XI, 25, 1, se dice que sólo los eduos obtuvieron el senatorum in Vrbe ius. ${ }^{58}$

Por mi parte, opino que la ambigüedad del primer párrafo del capítulo 25 de los Anales refleja claramente la ambigüedad del pensamiento de Tácito, en general, frente al principado; por una parte, Tácito acepta la decisión de Claudio de incorporar al senado romano al elemento extranjero; baste recordar que su padre probablemente fue originario de la Galia Narbonense, amén de que, con seguridad, lo fue su suegro, Julio Agrícola; sin embargo, por la otra, Tácito considera que el proceso de incorporación de los extranjeros en el gobierno del imperio no puede ser masivo e indiscriminado, sino que debe ser el resultado de una cuidadosa selección, pues es un hecho que ni todos los extranjeros son Balbos, ni a todo el mundo se le puede comparar con aquellos varones no menos ilustres que los Balbos, provenientes de la Galia Narbonense, como su padre y como el padre de su esposa; en consecuencia, en este asunto tan importante para el desarrollo del imperio romano, se tiene que actuar con prudencia, aplicando un riguroso y atento criterio de selección, en busca de los mejores elementos, como lo hizo el senado romano al otorgar el ius honorum

57 Ídem, p. 68.

58 Ídem, pp. 502-503. 
plenum, no a todos los notables de la Galia llamada Comata, sino sólo, con base en una cuidadosa selección y en atención a sus méritos, a los eduos, por ser éstos los mejores entre ellos.

\section{Bibliografía}

Carcopino, J., "La Table Claudienne de Lyon", en Points de vue sur l'imperialisme romain, Paris, 1934, pp. 159-199.

Svetoni Tranquilli, C., De uita Caesarum, tomo II, texto y traducción de Henri Ailloud, París, Société d' Edition "Les Belles Lettres", 1980.

Courbaud, E., Les procédés d' art de Tacite dans les "Histoires", Paris, Hachette, 1918.

De Vivo, A., Tacito e Claudio. Storia e codificazione letteraria, Napoli, Liguori Editore, 1980.

Gerber, A., y A. Greef, Lexicon Taciteum, Hildesheim, Georg Olms, 1962.

Live, Tite, Histoire Romaine, vol. IV, livr. IV, texto establecido por Jean Bayet, traducción de Gastón Baillet, Paris, "Les Belles Lettres", 1965.

MarCheSI, C., Tacito, Milano-Messina, Giuseppe Principato, 1955.

Michel, A., Tacito e il destino dell' impero, Torino, Giulio Einaudi Ed., 1973.

Paratore, E., Tacito, Roma, Edizioni dell' Ateneo Romano, 1962.

Questa, C., Studi sulle fonti degli “Annales” di Tacito, Edizioni dell' Ateneo (Nuovi saggi, 28), 1960.

Syme, R., Tacito, 2 vols., traducción de Carla Marocchi, Brescia, Paideia (Biblioteca di Studi Classici, 5), 1967 y 1971, respectivamente.

TACITE, Annales: Livres I-III, IV-VI, XI-XII, XIII-XVI, texto establecido y traducido por P. Wuilleumier, Paris, "Les Belles Lettres", 1974, 1975, 1976 y 1978, respectivamente.

-, Oeuvres complètes, traducción, presentación y notas de Pierre Grimal, Paris, Gallimard (Biblioteca de la Pléiade, 361), 1990. 
TÁcito, C., Historias I-II, introducción, traducción y notas de José Tapia Zúñiga, México, unAm (Bibliotheca Scriptorum Graecorum et Romanorum Mexicana), 1995.

-, Anales I-II, introducción, traducción y notas de José Tapia Zúñiga, México, unAm (Bibliotheca Scriptorum Graecorum et Romanorum Mexicana), 2002.

-, Anales: Libros I-VI y XI-XVI, introducción, traducción y notas de José L. Moralejo, Madrid, Gredos (Biblioteca Clásica Gredos, 19 y 30), 1979 y 1980.

-, Annali, 2 vols., introducción, traducción y notas de Lidia Storoni Mazzolani, Roma, Newton Compton Editori, 1995.

-, Annali: Dalla morte del divo Augusto, traducción de E. Oddone, introducción y notas de M. Caltabiano, Milán, Rusconi (I Cassici di Storia), 1978.

-, Annali: Libro XI, introducción y comentarios de Francisco Mascialino, Milán-Roma, Societá Editrice Dante Alighieri, 1992. 